\title{
"Adjacent" Substituted Phthalocyanines
}

\author{
K. J. M. Nolan, M. Hu, C. C. Leznoff*
}

Department of Chemistry, York University, North York, Ontario, Canada. M3J 1 P3

FAX: 416-736-5936, e-mail: leznoff@yorku.ca

Abstract: 2,3,9,10-Tetrakis(3,3-dimethyl-1-butynyl)phthalocyanine and 2,3,9,10-tetramethoxyphthalocyanine were prepared by the condensation of a "half" phthalocyanine intermediate (prepared from 4,5-bis(3,3-dimethyl-1-butynyl)phthalonitrile or phthalonitrile) with phthalonitrile and 4,5-dimethoxyphthalonitrile respectively.

Recently, much interest has been focussed on "opposite" and "adjacent" substituted phthalocyanines (Pcs). These Pcs have very interesting spectroscopic properties and potential applications in non-linear optics and the photodynamic therapy of cancer. ${ }^{1}$ Although some oppositely substituted Pcs can be efficiently prepared by various methods ${ }^{2}$, there have been no reports on an efficient method of preparing adjacently substituted Pcs. Previous workers have used mixed condensations of two different phthalonitriles to obtain the adjacently substituted $\mathrm{Pc}^{3}$ This approach has many disadvantages since all six possible substituted Pcs, including the opposite and adjacent ones, are produced and exhaustive chromatography is required to separate all $\mathrm{Pc}$ products. We report, herein, a more efficient method of preparing an adjacently substituted Pc. This new method involves using a "half" Pc intermediate and results indicate that no oppositely substituted phthalocyanine products are made.

The preparation of half intermediates has been previously reported, ${ }^{4}$ but it was proposed that only phthalonitriles containing electronwithdrawing groups could give such stable intermediates. Recently, we synthesized 4,5-bis(3,3-dimethyl-1-butynyl)phthalonitrile (1). ${ }^{5}$ Since this phthalonitrile contains two weakly electron-withdrawing groups, we expected that conversion to a "half" Pc intermediate could be achieved. The method, reported by Oliver and Smith ${ }^{4}$ was used to convert 1, phthalonitrile (2), and 4,5-dimethoxyphthalonitrile (3) to the "half" intermediates 4-6 respectively, except that the temperature was lowered to refluxing methanol.

Analysis of the crude products, derived from $1-3$ by FAB mass (ms) and ${ }^{\text {I }} \mathrm{H}$ nuclear magnetic resonance (NMR) spectroscopy indicated that the predominant products from 1 and 2 were the "half" phthalocyanine intermediates (dimers) 4 and $5,{ }^{6}$ while 3 gave only a trace of dimer 6 . In the reaction of $\mathbf{1}$ and $\mathbf{2}$, minor amounts of the "quarter" phthalocyanine intermediate (monomer) 7 and 8 were detected, but the reaction of 3 gave mostly monomer 9 .

Attempts were made at purifying 4 by column chromatography, but demetallation of the lithium and hydrolysis of the methoxy group likely occurred. Gel-permeation chromatography (GPC) using SX-4 Beads (Bio-Rad) and tetrahydrofuran (THF) as the eluting solvent was attempted but partial demetallation occurred. It was decided that the crude intermediates 4 and 5 would be used in the synthesis of an adjacent $\mathrm{Pc}$

Crude 4 was treated with a large excess of 2 in $2-\mathrm{N}, \mathrm{N}-$ dimethylaminoethanol (DMAE) at $75^{\circ} \mathrm{C}$. After $3 \mathrm{~h}, \mathrm{Zn}(\mathrm{OAc})_{2}$ was added and the temperature lowered to $60^{\circ} \mathrm{C}$ and allowed to stir for an additional $24 \mathrm{~h}$. The reaction mixture was then diluted with $20 \%$ methanol/water and the pigment dried and collected. The crude product was then suspended in benzene until all soluble Pcs were completely removed. Flash chromatography using chloroform as the eluting solvent, was performed on the soluble Pcs collected from the above extraction. The first of five coloured fractions contained a trace amount of a zinc octaalkynylphthalocyanine (10), the second fraction contained a mixture of zinc octaalkynyl-(10), hexaalkynyl-(11), and tetraalkynylphthalocyanines (12) plus possibly (13), the third band was pure 2,3,9,10-tetrakis(3,3-dimethyl-1-butynyl)phthalocyaninato zinc (II) $^{7}$ (12), the fourth band was a mixture of (12) and 2,3-bis(3,3dimethyl-1-butynyl)phthalocyaninato zinc (II) (14), and the fifth band was pure $14^{7}$. All fractions containing 12 and 14 were further purified by GPC on SX-2 beads (Bio-Rad) with THF as the eluting solvent. All Pcs were separated after one column and the yields of 12 and 14 were $20 \%$ and $10 \%$ respectively, while only trace amounts of 10 and 12 were obtained (less than 1\%) (Scheme).<smiles></smiles>

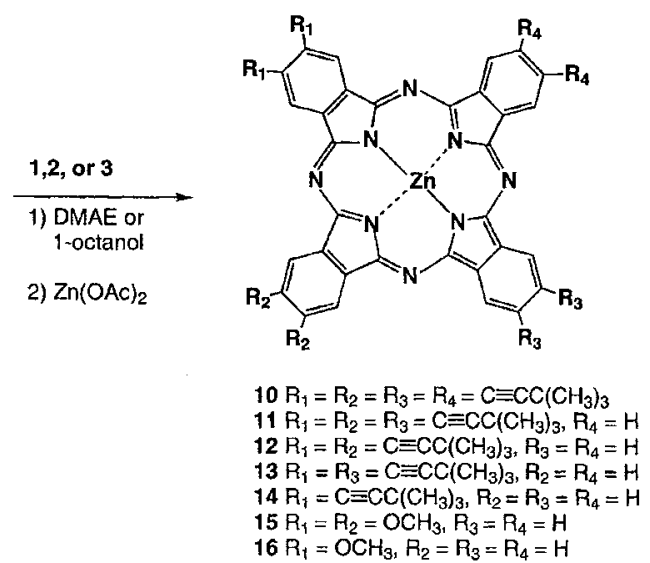

Phthalocyanine 12 was identified as the adjacent isomer by UV-visible spectroscopy. It has been found by both molecular orbital calculations ${ }^{8}$ and experiment ${ }^{3}$ that metallophthalocyanines with $C_{2 \gamma}$ symmetry should exhibit only one peak for the Q-band of the phthalocyanines and each triple bond should cause a redshift of the Q-band by $4-5 \mathrm{~nm}$. The observed Q-band at $692 \mathrm{~nm}$ is in accordance with this. ${ }^{7}$

The ${ }^{1} \mathrm{H}$ NMR spectrum of 12 in pyridine $-d_{5}\left(10^{-3} \mathrm{M}\right.$ at $\left.300 \mathrm{~K}\right)$ exhibits, in the aromatic region, two singlets of equal intensity along with two multiplets for the protons of the unsubstituted benzo rings. The combined intensities of the two singlets is equal to the intensity of each multiplet as it should be for $\mathbf{1 2}$. As the concentration was increased to $10^{-2} \mathrm{M}$, the two singlets converged, most likely due to aggregation.

Similarly, treatment of the unsubstituted dimer 2 with 4,5dimethoxyphthalonitrile $(3)^{9}$, but in 1 -octanol ${ }^{10}$ gave almost exclusively 
2,3,9,10-tetramethoxyphthalocyaninato zinc (II) (15) and 2,3dimethoxyphthalocyaninato zinc (II) (16). The ${ }^{1} \mathrm{H}$ NMR spectrum of (15) clearly exhibits absorptions for the two different methoxy groups and two aromatic singlets at 9.24 and $9.19 \mathrm{ppm}$.

We have demonstrated that adjacent substituted phthalocyanines can be obtained in reasonably good yields with few by-product compounds present. Since 2 can be converted to 5 with little by-product, it is apparent that electron withdrawing substituents are not a necessary requirement for the formation of stable "half" phthalocyanine moieties and the way is opened to develop this strategy as a general method to prepare adjacent substituted phthalocyanines.

Acknowledgements. The authors are grateful to the Natural Sciences and Engineering Research Council of Canada for support of this research.

\section{References and Notes}

(1) Van Lier, J. E. In Photodynamic Therapy of Neoplastic Disease, Vol. I; Kassel, D., Ed.; CRC: Boca Raton, FL, 1990; p 279. Rosenthal, I. In Phthalocyanines: properties and applications, Vol. 4; Leznoff, C. C.; Lever, A. B. P.; VCH: New York, NY, 1996; p 481.

(2) Idelson, E. M. U.S. Patent 4061654, 1977; Chem. Abstr. 1977, 88, $171797 \mathrm{~m}$. Young, G.; Onyebuagu, W. J. Org. Chem. 1990, 55, 2155. Kobayashi, N.; Ashida, T.; Osa, T. Chem. Lett. 1992, 2031.

(3) Ikeda, Y.; Konami, M.; Hatano, M.; Mochizuki, M. Chem. Lett. 1992, 763. Linssen, T. G.; Hanack, M. Chem. Ber. 1994, I27, 2051.

(4) Oliver, S. W.; Smith, T. D.; J. Chem. Soc. Perkin Trans 2 1987, 1587. Hurley, T. J.; Robinson, M. A.; Trotz, S. I. Inorg. Chem. $1967,6,389$.

(5) Terekhov, D. S.; Nolan, K. J. M.; McArthur, C. R.; Leznoff, C. C. J. Org. Chem. 1996, 61, 3034.

(6) Spectroscopic data for dimers 4 and 5: for $4{ }^{1} \mathrm{H}$ NMR (400MHz, pyridine- $\left.d_{5}\right) \delta 7.99(\mathrm{br} \mathrm{s}, 2 \mathrm{H}), 7.55(\mathrm{br} \mathrm{s}, 2 \mathrm{H}), 3.34(\mathrm{~s}, 3 \mathrm{H}), 1.41$ (d, $36 \mathrm{H}$ ); FAB-MS for $\mathrm{C}_{41} \mathrm{H}_{43} \mathrm{~N}_{4} \mathrm{OLi}$ (m/z intensity, \%) $615(\mathrm{M}+1$, 100), $609(30), 600(30), 319$ (20): for 5 FAB-MS for
$\mathrm{C}_{17} \mathrm{H}_{11} \mathrm{~N}_{4} \mathrm{OLi}(\mathrm{m} / \mathrm{z}$ intensity, \%) $295(\mathrm{M}+\mathrm{l}), 88), 289(78), 280$ (51).

(7) Spectroscopic data for Pcs 12, 14, 15, and 16: for $12 \mathrm{UV}$-vis $\left(\mathrm{CHCl}_{3}\right) \lambda_{\max } / \mathrm{nm}(\log \varepsilon) 692(5.16), 624(4.42), 356(4.78) ;{ }^{1} \mathrm{H}$ NMR (400 MHz, pyridine- $d_{5}$ ) $\delta 9.91$ (s, 2H), 9.89 (s, 2H), 9.73 $(\mathrm{m}, 4 \mathrm{H}), 8.27(\mathrm{~m}, 4 \mathrm{H}), 1.58(\mathrm{~s}, 36 \mathrm{H}) ;{ }^{1} \mathrm{H}$ NMR (benzene- $\left.\mathrm{d}_{6}\right) \delta$ $9.89(\mathrm{~s}, 2 \mathrm{H}), 9.85(\mathrm{~s}, 2 \mathrm{H}), 9.56(\mathrm{~m}, 4 \mathrm{H}), 8.04(\mathrm{~m}, 4 \mathrm{H}), 1.71(\mathrm{br} \mathrm{s}$, 36H); FAB-MS for $\mathrm{C}_{56} \mathrm{H}_{48} \mathrm{~N}_{8} \mathrm{Zn}(\mathrm{m} / \mathrm{z}$ intensity, \%) $898(\mathrm{M}+\mathrm{l}$, 100). For $14 \mathrm{CV}$-vis $\left(\mathrm{CHCl}_{3}\right) \lambda_{\max } / \mathrm{nm}$ 684, 672, 610, 350; FABMS for $\mathrm{C}_{44} \mathrm{H}_{32} \mathrm{~N}_{8} \mathrm{Zn}(\mathrm{m} / \mathrm{z}$ intensity, \%) $735(\mathrm{M}+1,100)$. For 15 UV-vis (THF) $\lambda_{\max } / \mathrm{nm}(\log \varepsilon) 668$ (5.11), 640 (4.32), 604 (4.34), 354 (4.68); ${ }^{1} \mathrm{H}$ NMR $\left(400 \mathrm{Mz}\right.$, pyridine- $\left.d_{5}\right) \delta 9.79(\mathrm{~d}, \mathrm{~J}=7.4 \mathrm{~Hz}$, $2 \mathrm{H}), 9.71(\mathrm{~d}, \mathrm{~J}=7.4 \mathrm{~Hz}, 2 \mathrm{H}), 9.24(\mathrm{~s}, 2 \mathrm{H}), 9.19(\mathrm{~s}, 2 \mathrm{H}), 8.25-8.18$ $(\mathrm{m}, 4 \mathrm{H}), 4.31(\mathrm{~s}, 6 \mathrm{H}), 4.11(\mathrm{~s}, 6 \mathrm{H})$; FAB-MS for $\mathrm{C}_{36} \mathrm{H}_{24} \mathrm{~N}_{8} \mathrm{O}_{4} \mathrm{Zn}$ $(\mathrm{m} / \mathrm{z}$ intensity, \%) $700(\mathrm{M}+4,65), 699(\mathrm{M}+3,100), 698(\mathrm{M}+2$, 84), $697(\mathrm{M}+1,75), 696(\mathrm{M}, 95)$. For $16{ }^{1} \mathrm{H}$ NMR $(400 \mathrm{MHz}$, pyridine- $\left.d_{5}\right) \delta 9.75(\mathrm{~m}, 8 \mathrm{H}), 8.23(\mathrm{~m}, 6 \mathrm{H})$; FAB-MS for $\mathrm{C}_{34} \mathrm{H}_{20} \mathrm{~N}_{8} \mathrm{O}_{2} \mathrm{Zn}(\mathrm{m} / \mathrm{z}$ intensity, \%) $638(\mathrm{M}+2,96), 637(\mathrm{M}+1$, 90), $636(\mathrm{M}, 100)$.

(8) Konami, H.; Ikeda, Y,; Hatano, M.; Mohizuk, K. J. Mol. Physics 1993, 80, 153.

(9) Metz, J.; Schneider, O.; Hanack, M. Inorg. Chem. 1984, 23, 1065.

(10) Typical Experimental Procedure: To $20 \mathrm{~mL}$ of freshly distilled methanol was added $0.07 \mathrm{~g}$ of lithium $(10 \mathrm{mmol})$ and $2.56 \mathrm{~g} \mathrm{(20}$ mmol) of 2 . The solution was refluxed for $2 \mathrm{~h}$ under argon. To 2 $\mathrm{mL}(2 \mathrm{mmol}$ of 2$)$ of the dark green solution was added $1.84 \mathrm{~g}(10$ mmol) of 4,5-dimethoxyphthalonitrile (3) in $10 \mathrm{~mL}$ of 1-octanol. The mixture was heated to $100^{\circ} \mathrm{C}$ and stirred overnight. Zinc acetate was added to the mixture, which was stirred for another 8 $\mathrm{h}$. The mixture was poured into $50 \mathrm{~mL}$ of methanol and water (1:1) to give a blue precipitate which was collected by centrifugation. The residue was passed through a silica gel column to remove some impurities by eluting with THF and hexane (1:1). Further purification was performed by GPC on Bio-beads gel (SX2) and two main fractions, $\mathbf{1 5}$ and $\mathbf{1 6}$ were collected in 28 and 22\% yields, respectively. Compounds $\mathbf{1 5}$ and $\mathbf{1 6}$ are both blue solids mp $>320^{\circ} \mathrm{C}$. 